\title{
PULVERIZAÇÃO FOLIAR E FERTIRRIGAÇÃO COM SILÍCIO NOS ATRIBUTOS FÍSICO-QUÍMICOS DE QUALIDADE E ÍNDICES DE COLORAÇÃOO DO MORANGO
}

\author{
Leaf spraying and fertirrigation with silicon on the physicochemical \\ attributes of quality and coloration indices of strawberry \\ Felipe Campos Figueiredo ${ }^{1}$, Priscila Pereira Botrel ${ }^{2}$, César Pereira Teixeira ${ }^{1}$, \\ Lauro Luís Petrazzini ${ }^{3}$, Marco Locarno ${ }^{4}$, Janice Guedes de Carvalho
}

\begin{abstract}
RESUMO
Neste trabalho, objetivou-se avaliar o efeito da aplicação de silício via foliar e em fertirrigação, nos atributos físico-químicos de qualidade e índices de coloração do morango cultivado em casa de vegetação. O delineamento experimental utilizado foi inteiramente casualizado em um fatorial $5 \times 2$, com cinco concentrações de silicato de potássio pulverizado via foliar $\left(0 ; 0,25 ; 0,5 ; 0,75\right.$ e $1 \%$ de Sili-K $\left.{ }^{\circledR}\right)$, semanalmente, na presença e ausência de Si na solução de fertirrigação $\left(0\right.$ e $\left.94 \mathrm{mg} \mathrm{dm}^{-3}\right)$, com cinco repetições por tratamento. Os "frutos" analisados foram colhidos 110 dias após o plantio para determinação de ácido cítrico, pH de polpa, pectina total, pectina solúvel, solubilização da pectina, açúcares totais, glicose, sacarose e os índices de L e A de coloração externa e interna dos "frutos". A aplicação foliar de silicato de potássio associado ou não com Si em fertirrigação altera os teores de ácido cítrico e pH de polpa e eleva os teores totais de açúcares e glicose. A presença de Si em fertirrigação eleva os teores de sacarose dos "frutos". Associado ao Si em fertirrigação, o aumento das concentrações de silicato de potássio aplicado via foliar reduz a solubilização da pectina que são sempre menores nos tratamentos ausentes de Si em fertirrigação. As concentrações de silicato de potássio aplicado via foliar na presença ou ausência de Si em fertirrigação alteram a luminosidade e coloração interna e externa dos "frutos".
\end{abstract}

Termos para indexação: Fragaria X ananassa (Weston) Duchesne, adubação foliar, silicato de potássio.

\begin{abstract}
The objective of this research was to evaluate the effect of the application of potassium silicate via foliar and in fertirrigation on the physcochemical attributes, quality and coloration indices of strawberry fruits. The experimental design utilized was completely randomized in a 5 x 2 factorial with five concentrations of potassium silicate $\left(0 ; 0.25 ; 0.5 ; 0.75\right.$ and $1 \%$ of Sili-K $\left.{ }^{\circledR}\right)$, weekly, in presence and absence of $\mathrm{Si}$ in the fertirrigation solution $\left(0\right.$ and $\left.94 \mathrm{mg} \mathrm{dm}^{-3}\right)$, with five replicates in each treatment. The "fruits" analyzed were collected 110 days after planting for determination of citric acid, pulp $\mathrm{pH}$, total pectin, soluble pectin, pectin solubilization, total sugars, glucose and sucrose. The analyzed coloration indices were: L and A indices of external and internal coloration of the "fruits". The potassium silicate foliate application reduced the citric acid content and pulp pH and raises the total contents of sugars and glucose. Associated to $\mathrm{Si}$ in fertirrigation, increased concentrations of potassium silicate foliar applied reduced the solubilization of pectin that are always smaller in absence of $\mathrm{Si}$ in fertirrigation. The concentrations of leaf-applied potassium silicate in the presence or absence Si fertirrigation change the brightness and the internal and external color of the "fruits".
\end{abstract}

Index terms: Fragaria X ananassa (Weston) Duchesne, foliar fertilization, potassium silicate.

(Recebido em 24 de julho de 2008 e aprovado em 20 de novembro de 2008)

\section{INTRODUÇÃO}

O morangueiro pertence à família das rosáceas e ao gênero Fragaria L. cuja infrutescência possui grande aceitação comercial por sua aparência, aroma e sabor atrativo, características que o colocam como uma das mais saborosas sobremesas (Henrique \& Cereda, 1999).

A aplicação foliar de fontes de silício líquido solúvel tem sido foco de várias pesquisas pela sua eficácia, praticidade, uso de doses menores e também como adaptável aos pulverizadores normalmente utilizados por muitos produtores. Os resultados são bastante promissores em várias culturas, mesmo as que não são acumuladoras do elemento como o café, soja, alface, algodão, milho (Reis et al., 2007).

As principais funções atribuídas ao silício são: aumento da resistência a patógenos, alterações estruturais e metabólicas como observadas por Wang \& Galletta

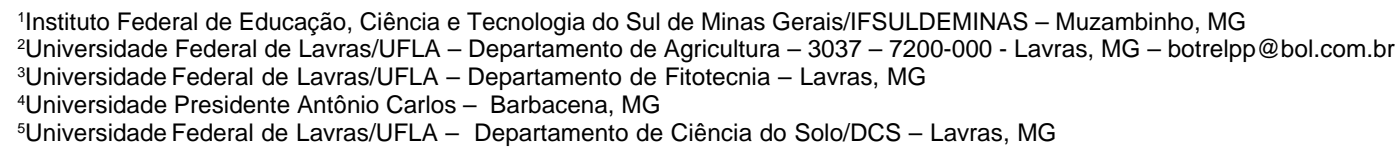


(1998), onde a aplicação foliar de silicato de potássio proporcionou aumento no conteúdo de clorofila, crescimento de plantas e alterações dos teores de ácidos orgânico nas folhas de morangueiro.

As alterações metabólicas e estruturais causadas pelo silício podem influenciar suas características sensoriais, melhorando a vida útil pós-colheita, taxa respiratória, e a suscetibilidade ao desenvolvimento de agentes patogênicos (Henrique \& Cereda, 1999). Adicionalmente, o uso de sanificantes poderia ser utilizado como uma forma de preservar a qualidade de morangos da cultivar Oso Grande minimamente processados, por manter baixas a contagem de fungos filamentosos e leveduras por até 12 dias (Reis et al., 2008).

Importantes atributos de qualidade do morango como aparência (tamanho, forma e defeitos), sabor, odor (flavor), valor nutritivo e ausência de defeitos, sofrem modificações em pós-colheita (Chitarra, 1999). Os açúcares totais representam os carboidratos de baixo peso molecular e são responsáveis pela doçura, sabor e aroma, pela cor atrativa e pela textura que são representados principalmente pela glicose e sacarose (Lima, 1999). Os teores de açúcares tendem a aumentar com o amadurecimento concomitante com a redução da acidez (Chitarra \& Chitarra, 2005). A acidez revelada pelo pH de polpa são atributos físicoquímicos importantes na definição da finalidade de uso das variedades. A característica de $\mathrm{pH}$ torna difícil o desenvolvimento de cultivares de dupla aptidão, já que as exigências para cultivares de uso industrial e consumo in natura são opostas.

A avaliação da cor é outro importante atributo para o produtor, pois, determina as condições ideais de colheita e comercialização dos "frutos". Os "frutos" de coloração vermelha, forte e brilhante são os preferidos, embora a cor, na maioria dos casos, não contribui para um aumento efetivo no valor nutritivo ou qualidade sensorial do produto (Chitarra \& Chitarra, 2005). Em outro estudo, Sacks \& Shaw (1993) concluíram que o tempo de armazenamento tornam os "frutos" mais escuros e cromáticos, denotados por menores valores de $\mathrm{L}^{*}$ (luminosidade) e elevados valores de croma, enquanto que, na coloração externa, quanto mais amadurecem os "frutos", estes se apresentam mais escuros e menos cromáticos.

Nesse sentido, foi desenvolvido o presente trabalho, com o objetivo de avaliar o efeito da aplicação de silicato de potássio via foliar e em fertirrigação, nos atributos físico-químicos e nos índices de coloração dos "frutos" de morango.

\section{MATERIAL E METODOS}

O experimento foi conduzido em casa de vegetação da Universidade Federal de Lavras. As plantas da variedade Oso-Grande foram cultivadas em vasos de dois litros contendo o substrato Plantmax ${ }^{\circledR}$ enriquecido com $131 \mathrm{mg} \mathrm{dm}^{-3}$ de P, $309 \mathrm{mg} \mathrm{dm}^{-3}$ de Ca e $200 \mathrm{mg} \mathrm{dm}^{-3} \mathrm{~S}$ na forma de superfosfato simples, plantadas em 13 de setembro de 2007.

O delineamento experimental utilizado foi inteiramente casualizado em um esquema fatorial $5 \times 2 \mathrm{com}$ cinco concentrações de silicato de potássio pulverizado sobre as folhas $(0 ; 0,25 ; 0,5 ; 0,75$ e $1 \%)$ na presença ou ausência de Si na solução de fertirrigação (0 e $\left.94 \mathrm{mg} \mathrm{dm}^{-3}\right)$, com cinco repetições em cada tratamento, contendo um vaso por parcela, perfazendo um total de 50 vasos. A fonte de silicato de potássio foi o Sili- $\mathrm{K}^{\circledR}$ cujas garantias são: $12,2 \%$ de $\mathrm{Si} ; 15 \%$ de $\mathrm{K}_{2} \mathrm{O}(\mathrm{p} / \mathrm{p})$ e densidade de $1,4 \mathrm{~kg} \mathrm{~L}^{-1}$.

As soluções de fertirrigação continham: $2500 \mathrm{mg} \mathrm{L}^{-1}$ de $\mathrm{N}$ e $\mathrm{K} ; 187,5 \mathrm{mg} \mathrm{L}^{-1}$ de $\mathrm{Mg} ; 3,1 \mathrm{mg} \mathrm{L}^{-1}$ de B; 9,4 mg L-1 de

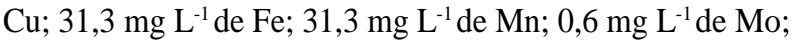
$31,3 \mathrm{mg} \mathrm{L}^{-1}$ de $\mathrm{Zn}$ e na solução com silício foi utilizada esta mesma composição, porém, com $94 \mathrm{mg} \mathrm{L}^{-1}$ de Si na forma de silicato de potássio onde o potássio do produto foi descontado, variando somente a concentração de $\mathrm{Si}$.

As aplicações foliares foram realizadas semanalmente durante todos o cultivo, e as fertirrigações duas vezes por semana com aplicação de $10 \mathrm{~mL}$ da solução nutritiva até os 84 dias de cultivo, aumentando a partir daí para três vezes semanais do até o final do trabalho que se deu aos 140 dias.

A colheita dos "frutos" foi realizada semanalmente, no entanto, somente foram analisados aqueles colhidos aos 110 dias após o plantio, quando as plantas encontravam-se no auge da produção.

As análises foram realizadas no Departamento de Ciência dos Alimentos da Universidade Federal de Lavras onde o $\mathrm{pH}$ foi determinado por potênciometria em eletrodo de vidro pelo aparelho Micronal modelo B371, segundo normas da Association of Official Analytical Chemistry AOAC (2000).

A acidez titulável expressa ácido cítrico ou foi determinada por titulação do filtrado com solução padronizada de $\mathrm{NaOH} 0,1 \mathrm{~N}$ pela técnica do Instituto Adolfo Lutz (1985).

Os açúcares totais, glicose e sacarose foram extraídos pelo método de Lane-Enyon, citado pela AOAC (2000) e o doseamento, segundo a técnica de Somogyi adaptada por Nelson (1944) e leitura pelo espectrofotômetro. 
A extração das substancias pécticas foi realizada segundo a técnica descrita por McCready \& McComb (1952) e a determinação colorimétrica realizada pela reação de carbazol, segundo técnica de Bitter \& Muir (1962). A solubilização da pectina foi calculada pela porcentagem de pectina solúvel em relação a total pela seguinte equação: \% de solubilização = (pectina solúvel/pectina total) x 100 .

Os índices de coloração interna e externa foram determinados por meio de um colorímetro marca Minolta Ltda., modelo Chroma Meter CR - 3000 sistema L*a*b Color Space, por reflectância. Os parâmetros ou índices de cor, medidos em relação à placa de cor branca $(\mathrm{L}=97,02$; $a=5,37$ e $b=-3,63)$. Os índices avaliados foram: luminosidade (L) que compreende de 0 que é a coloração preta até 100 que corresponde a cor branca. $\mathrm{O}$ índice (A) compreende valores que vão do verde $(A=-60)$ ao vermelho $(A=+60)$.

Os dados foram submetidos à análise de variância pelo programa estatístico Sisvar 5.0, sendo que as concentrações de Si foram submetidas à análise de regressão 5\% de probabilidade.

\section{RESULTADOS E DISCUSSÃO}

Nas plantas cultivadas na ausência de Si na fertirrigação, os teores de ácido cítrico reduziram de forma quadrática com o aumento da concentração de silicato de potássio aplicado via foliar até uma concentração mínima estimada de $0,66 \%$, elevando ligeiramente os valores a partir desse ponto. Já, na presença de Si em fertirrigação, houve aumento linear dos teores, porém com baixo ajuste do modelo (Figura 1A).

Houve redução do $\mathrm{pH}$ da polpa de forma linear na proporção de 0,19 para cada unidade percentual da concentração de silicato de potássio aplicado via foliar na ausência de $\mathrm{Si}$ em fertirrigação; enquanto que, na presença desse elemento, houve diferenças significativas, mas o modelo quadrático obteve baixo ajuste. Esses resultados evidenciam que a redução do $\mathrm{pH}$ não se deve ao aumento dos teores de acido cítrico, mas, provavelmente, a elevação dos teores de outros ácidos que reduziram o $\mathrm{pH}$ e aumentaram a acidez da polpa (Figura 1B). Esse atributo seria importante para os "frutos" que se destinam à indústria, enquanto que, para o consumo in natura, o pH pouco ácido é mais aceitável. Isso possibilita a utilização do silicato de potássio para aumentar a acidez da polpa, direcionando os "frutos" para a indústria. $\mathrm{O}$ uso do silício pode ser uma alternativa onde existem dificuldades de obtenção de variedades com dupla aptidão, já que as exigências são opostas para uso industrial e consumo in natura.

Os teores de açúcares totais e glicose tiveram aumento de forma quadrática a partir da concentração estimada pelo modelo de $0,1 \%$ de silicato de potássio aplicados via foliar na ausência de Si em fertirrigação (Figuras 1C e 1D). Dos açúcares, a "frutos"e tem o poder mais adocicado seguido pela sacarose e glicose, portanto a elevação dos teores de glicose atribui um efeito sutil à doçura do morango (Chitarra \& Chitarra, 2005). Esse efeito poderá estar associado ao potássio que possui papel no metabolismo de açúcares (Taiz \& Zeiger, 2004; Malavolta, 2006), não obstante, o efeito do $\mathrm{Si}$ contribuiria para o processo, melhorando a utilização de água, nutrientes e aumento da atividade fotossintética (Reis et al., 2007). Contudo, o efeito sobre açúcares se deve ao produto silicato de potássio, pois nos tratamentos foliares os nutrientes não foram isolados.

Os teores de sacarose foram influenciados pela composição da fertirrigação, onde a presença de Si elevou em $17 \%$ os teores de sacarose dos "frutos" independente das aplicações foliares (Tabela 1). Nesse caso, fica evidente que o silício pode ter ação efetiva no metabolismo dos açúcares como evidenciado também por Wang \& Galleta (1998), os quais encontraram aumento de carboidratos solúveis nas folhas de plantas pulverizadas com silicato de potássio.

Na presença de Si em fertirrigação houve redução dos valores a partir da dose de $0,21 \%$ de silicato de potássio pulverizado via foliar para pectina solúvel e $0,27 \%$ para solubilização desta em relação à pectina total (Figura 1E e 1F). Ao mesmo tempo, os teores de pectina solúvel e solubilização desta, na ausência de Si em fertirrigação, mantiveram teores abaixo dos tratamentos que continham $\mathrm{Si}$ em fertirrigação. $\mathrm{O}$ aumento da pectina solúvel e da solubilização desta em relação a total se relaciona com uma menor resistência à manipulação pela maior maciez e alteração da textura do fruto em decorrência da redução da força de coesão entre as células (Chitarra \& Chitarra, 2005). Esta reação ocorre em função da liberação do cálcio e solubilização do polímero péctico por ação enzimática. Assim, o Si aplicado em fertirrigação aumentaria a maciez dos "frutos", enquanto a aplicação foliar pode torná-los mais firmes.

Houve redução de forma linear do índice $\mathrm{L}$ da coloração externa, tornando os "frutos" mais escuros com o aumento das concentrações de silicato de potássio pulverizadas na ausência de Si em fertirrigação (Figura 2A). 
Em morangos, vários trabalhos com componentes da cor foram realizados, tanto para a coloração externa quanto interna dos "frutos". Miszczak et al. (1995) e Paraskevopoulou-Paroussi et al. (1995) estudaram o comportamento dos componentes $\mathrm{L}^{*}, \mathrm{a}^{*} \mathrm{e} \mathrm{b}^{*} \mathrm{em}$ morangos inteiros pós-colheita e concluíram que os valores de $\mathrm{L}^{*}, \mathrm{a}^{*}$ e $\mathrm{b}^{*}$ diminuem com o tempo de armazenamento, ou seja, neste período os "frutos" amadurecem e tornam-se visualmente mais vermelhoescuros. O mesmo ocorreu com a utilização de silicato de
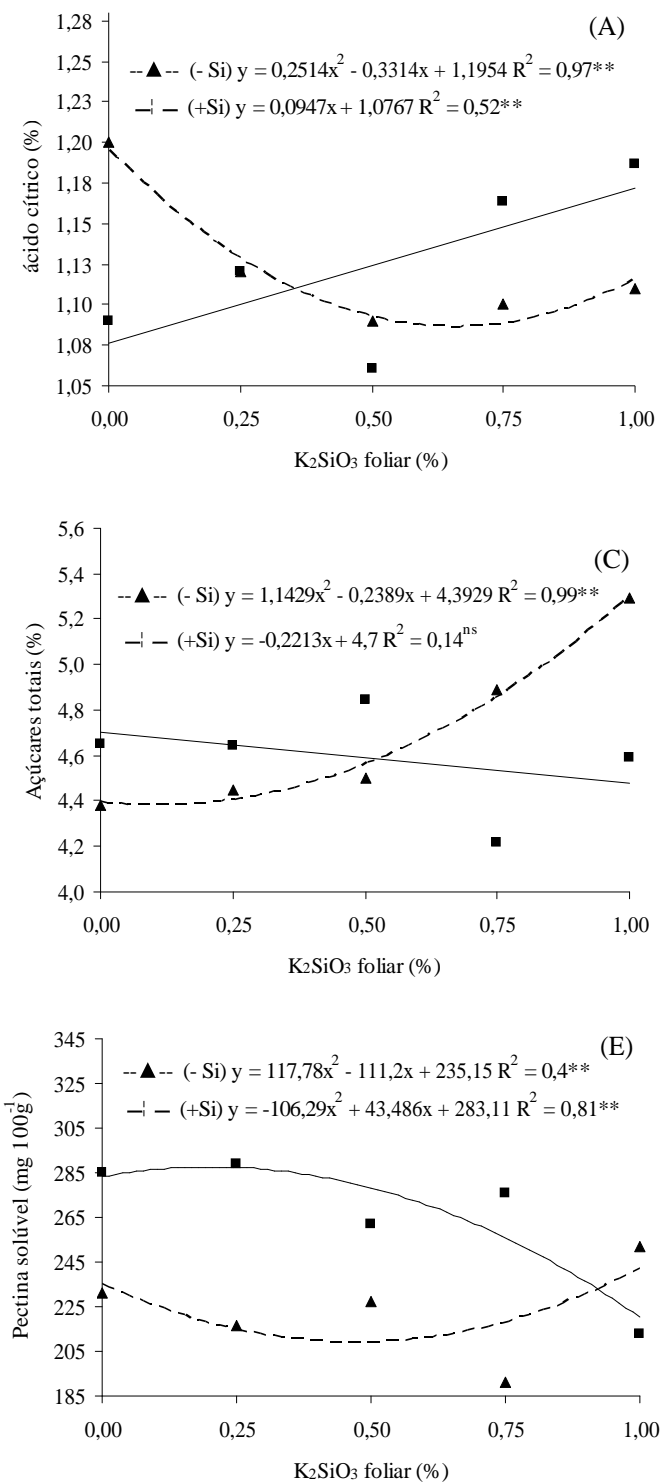

potássio na calda de pulverização para avaliação de coloração externa, onde os "frutos" tornaram-se mais escuros com o aumento das concentrações de silicato de potássio, havendo redução do índice L com o aumento das concentrações.

O índice A para cor externa sofreu redução linear dos valores com o aumento da concentração de silicato de potássio na calda de pulverização, o que significou uma redução da intensidade da cor vermelha (Figura 2B). Mas, na presença do $\mathrm{Si}$ em fertirrigação, os valores foram
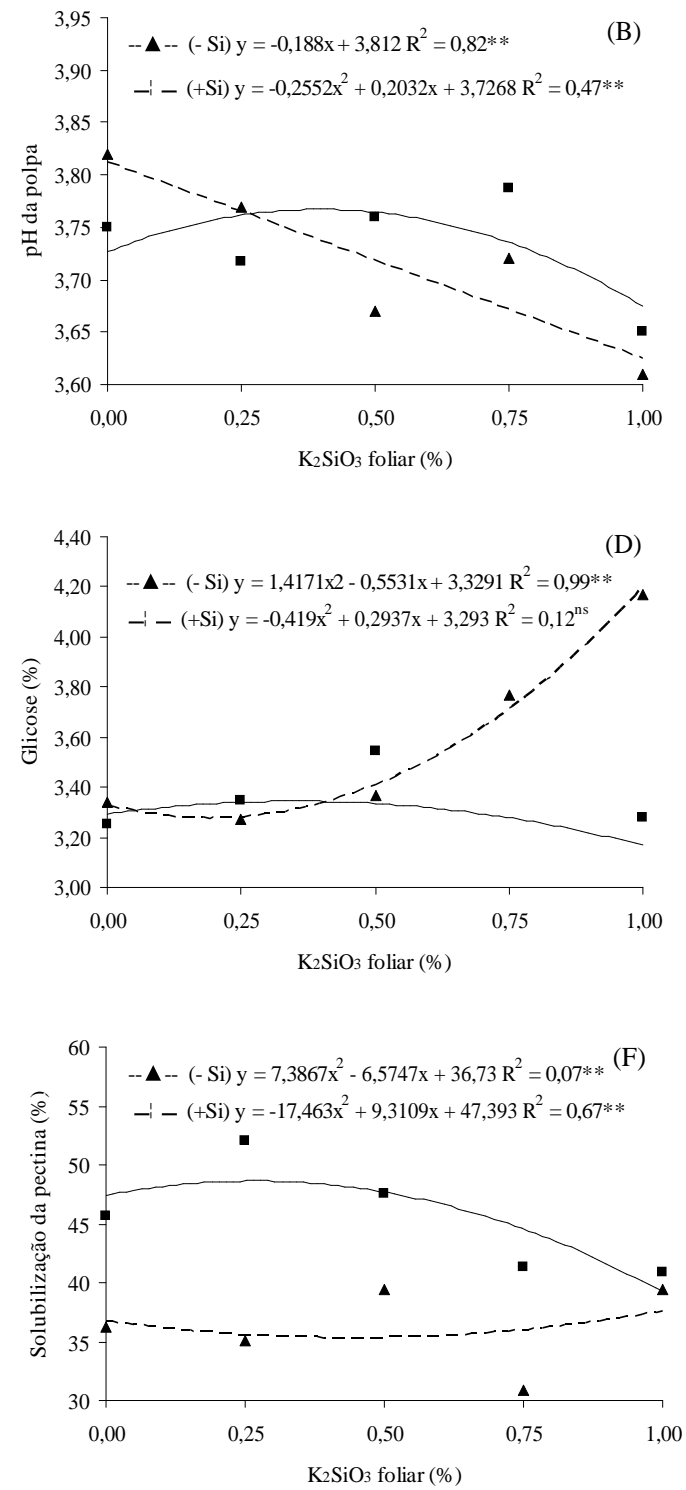

Figura 1 - Teores de ácido cítrico (A), pH de polpa (B), açúcares totais (C) e glicose (D), pectina solúvel (E) e solubilização da pectina (\%) de morangos provenientes de plantas pulverizadas com diversas concentrações de silicato de potássio na ausência $(-\mathrm{Si})$ ou presença $(+\mathrm{Si})$ de $\mathrm{Si}$ na fertirrigação. ** $\mathrm{p} \leq 0,01$ e ${ }^{\text {ns }}$ não significativo.

Ciênc. agrotec., Lavras, v. 34, n. 5, p. 1306-1311, set./out., 2010 
mais baixos, igualando e superando os valores de índice A nos tratamentos na ausência de Si na fertirrigação a partir da concentração de $0,75 \%$ de silicato de potássio pulverizado.

Tabela 1 - Teores de sacarose de morangos provenientes de plantas fertirrigadas com e sem Si.

\begin{tabular}{cc}
\hline Fertirrigação & Sacarose $(\%)$ \\
\hline Com silício & $1,24 \mathrm{a}$ \\
Sem silício & $1,06 \mathrm{~b}$
\end{tabular}

As médias não diferem entre si pelo teste $F$ a $1 \%$ de probabilidade.

O índice de luminosidade (L) interna do fruto foi influenciado de forma quadrática pela interação entre as concentrações de silicato de potássio na presença de $\mathrm{Si}$ em fertirrigação. Internamente o fruto se tornou mais escuro com o aumento da concentração silicato de potássio até a concentração estimada de $0,87 \%$ (Figura 2C). Já o índice A da cor interna foi influenciado somente pelas concentrações de silicato de potássio pulverizadas, independente da presença ou ausência de Si em fertirrigação, de modo que, o seu aumento resultou numa elevação linear destes índices, tornando o fruto mais vermelho internamente (Figura 2D). Essa mesma situação ocorreu normalmente com maior período de armazenamento onde os "frutos" se tornaram mais escuros e mais cromáticos internamente, e mais escuros e menos cromáticos externamente à medida que os "frutos" amadurecem (Sacks \& Shaw, 1993).

As diferenças de textura e cor são de fundamental importância para o produtor na escolha das variedades, mas é difícil diferenciar as texturas muito firmes, das firmes, e estas das pouco firmes, e também as tonalidades da cor vermelha. A caracterização quantitativa de caracteres fornece parâmetros mais exatos quanto às propriedades de textura e cor dos "frutos", e também contribui para definir a finalidade de uso das cultivares.
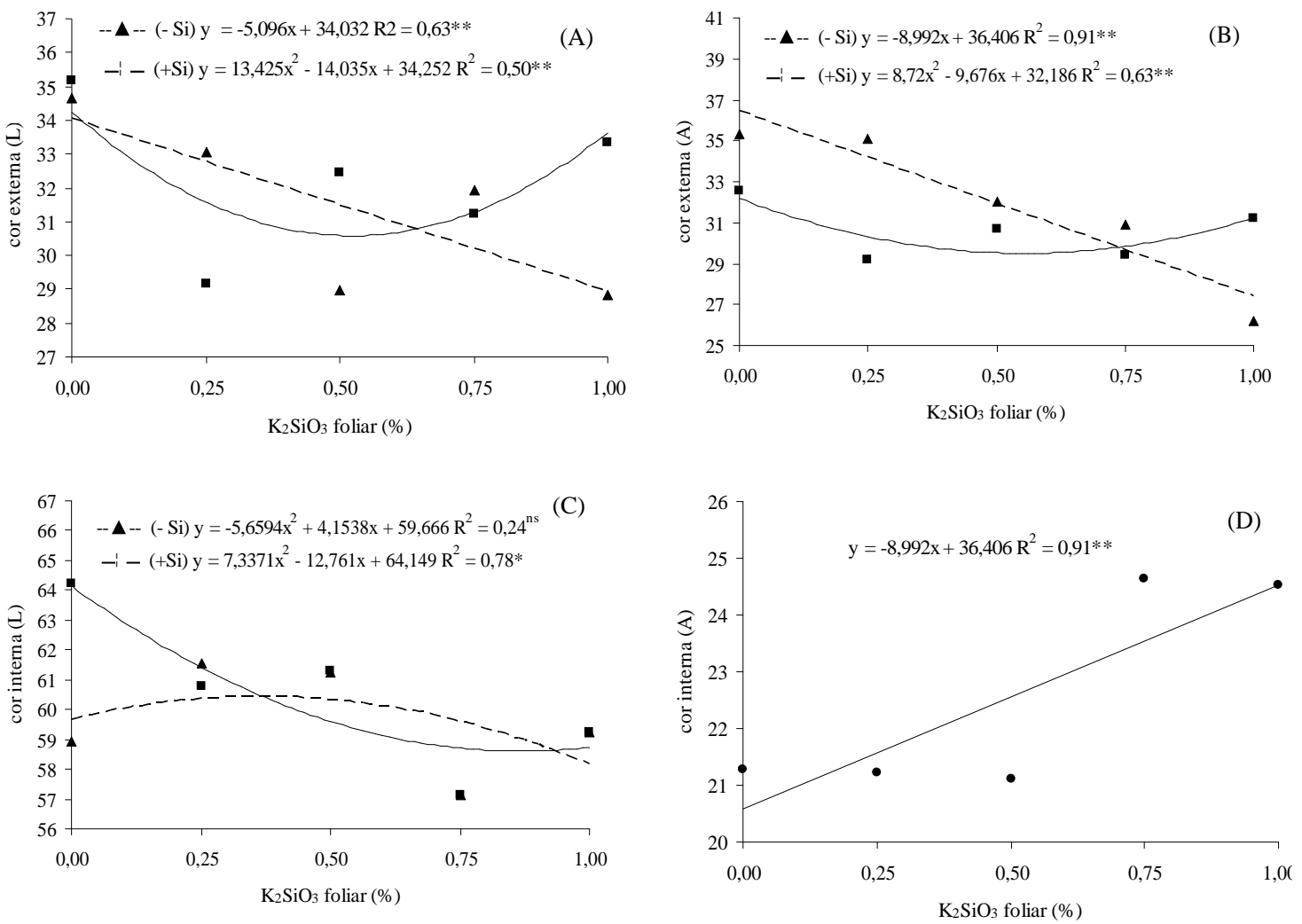

Figura 2 - Índice L (A) e índice A (B) de coloração externa e índice L (C) e índice A (D) de coloração interna de morangos provenientes de plantas pulverizadas com diversas concentrações de silicato de potássio na ausência (-Si) ou presença (+Si) de Si na fertirrigação. ** $\mathrm{p} \leq 0,01 ; * \mathrm{p} \leq 0,05$ e ${ }^{\text {ns }}$ não significativo. 


\section{CONCLUSÕES}

A aplicação foliar de silicato de potássio associado ou não com Si em fertirrigação altera os teores de ácido cítrico e pH de polpa e eleva os teores totais de açúcares e glicose.

A presença de Si em fertirrigação eleva os teores de sacarose dos "frutos".

Associado ao Si em fertirrigação, o aumento das concentrações de silicato de potássio aplicado via foliar reduz a solubilização da pectina que são sempre menores nos tratamentos na ausência de Si em fertirrigação.

As concentrações de silicato de potássio aplicado via foliar na presença ou ausência de Si em fertirrigação alteram a luminosidade e coloração interna e externa dos "frutos".

\section{AGRADECIMENTOS}

À CAPES e CNPq pelo fornecimento das bolsas e auxílio financeiro.

Às empresas UNAPROSIL, pelo auxílio financeiro e CAMPUS, pelo auxílio técnico.

\section{REFERÊNCIAS BIBLIOGRÁFICAS}

ASSOCIATION OF OFFICIAL ANALYTICAL CHEMISTRY. Official methods of analysis of the Association on Analytical Chemistry. 12.ed. Washington, 2000. 1015p.

BITTER, T.; MUIR, H.M.A. modified uronic acid carbazole reaction. Analytical Biochemistry, New York, v.34, n.4, p.330-334, 1962.

CHITARRA, A.B. Armazenamento de frutos e hortaliças por refrigeração. Lavras: UFLA, 1999. 58p.

CHITARRA, M.I.F.; CHITARRA, A.B. Pós-colheita de frutos e hortaliças: fisiologia e manuseio. Lavras: UFLA, 2005. 785p.

HENRIQUE, C.M.; CEREDA, M.P. Utilização de biofilmes na conservação pós-colheita de morango (Fragaria $x$ Ananassa Duch) cv IAC Campinas. Ciência e Tecnologia de Alimentos, Campinas, v.19, n.2, maio/ago. 1999.

INSTITUTO ADOLFO LUTZ. Normas analíticas, métodos químicos e físicos para a análise de alimentos. 3.ed. São Paulo, 1985. 533p.

LIMA, L.C.O. Qualidade, colheita e manuseio póscolheita de frutos de morangueiro. Informe
Agropecuário, Belo Horizonte, v.20, n.198, p.80-83, 1999.

MALAVOLTA E. Manual de nutrição mineral de plantas. São Paulo: Ceres, 2006. 638p.

McCREADY, P.M.; McCOMB, E.A. Extraction and determination of total pectic material. Analytical Chemistry, Washington, v.24, n.12, p.1586-1588, Dec. 1952.

MISZCZAK, A.; FORNEY, C.F.; PRANGE, R.K. Development of aroma volatiles and color during postharvest ripening of 'Kent' strawberries. Journal of the American Society for Horticulture Science, Washington, v.120, n.4, p.650-655, July 1995.

NELSON, N.A.A. Photometric adaptation of Sogomy method for the determination of glucose. The Journal of Biological Chemistry, Baltimore, v.135, n.1, p.136-175, May 1944.

PARASKEVOPOLOU-PAROUSSI, G.; VASSILAKAKIS, M.; DOGRAS, C. Effects of temperature, duration of cold storage and packaging on postharvest quality of strawberry fruit. Acta Horticulturae, Athens, v.379, p.337-344, June 1995.

REIS, K.C. dos; SIQUEIRA, H.H. de; ALVES, A.P.; SILVA, J.D.; LIMA, L.C.O. Efeito de diferentes sanificantes sobre a qualidade de morango cv. Oso Grande. Ciência e Agrotecnologia, Lavras, v.32, n.1, p.196-202, jan./fev. 2008.

REIS, T.H.P.; GUIMARÃES, P.T.G.; FIGUEIREDO, F.C.; POZZA, A.A.A.; NOGUEIRA, F.D.; RODRIGUES, C.R. 0 silício na nutrição e defesa de plantas. Belo Horizonte: EPAMIG, 2007. 124p. (EPAMIG. Boletim técnico, 82).

SACKS, E.J.; SHAW, D.V. Color change in fresh strawberry fruit of seven genotypes stored at $0{ }^{\circ} \mathrm{C}$. HortScience, Davis, v.28, n.3, p.209-210, 1993.

TAIZ, L.; ZEIGER, E. Fisiologia vegetal. 3.ed. Porto Alegre: Artmed, 2004. 719p.

WANG, S.Y.; GALLETTA, G.J. Foliar application and potassium silicate induces metabolic changes in strawberry plants. Journal Plant Nutrition, London, v.21, p.157-167, 1998. 